\title{
Efficacy of bacteriophage therapy against vancomycin-resistant Enterococcus feacalis in induced and non-induced diabetic mice
}

Ajay Kumar Oli ${ }^{1}$, Nagveni Shivshetty ${ }^{2}$, Likyat Ahmed ${ }^{3}$, ManjunathChavadi $^{4}$, Rahul N Kambar ${ }^{5}$ Kelmani Chandrakanth $\mathrm{R}^{*}$

\section{Ajay Kumar Oli}

Assistant Professor,

SDM Research Institute for Biomedical Sciences,

Shri Dharmasthala Manjunatheshwara University

Dharwad- 58009, Karnataka - India

Email.id.ajay.moli@gmail.com

Mobile.No. +919886079147

\section{Nagaveni Shivshetty}

Assistant Professor

Department of Microbiology

FST, GITAM (Deemed to be University),

Visakhapatnam-53004, Andhra Pradesh-India.

Email: nagaveni.shivshetty@ gitam.edu

Mobile. No. +919640696770

\section{Mohd Liyakat Ahmed}

Assistant Professor,

Department of Pharmacology,

Luqman College of Pharmacy

Kalaburagi- 585102, Karnataka- India

Email: mlapharm@ rediffmail.com

Mobile. No. +919663667452

4. Manjunath Chavadi

Research Scientist (Non-Medical),

Dept of Microbiology,

VRDL Laboratory,

Hassan Institute of Medical Science (HIMS)

Hassan-573201, Karnataka- India

Email ID: hicmanju@gmail.com

Mobile: +919742071346

5. Rahul N Kambar

Guest Lecturer

Department of Biotechnology

Gulbarga University

Kalburagi-585106, Karnataka-India

Email. ID. rahulkambar10@gmail.com

Mobile.No.9980920173 
bioRxiv preprint doi: https://doi.org/10.1101/2021.01.21.427594; this version posted January 21, 2021. The copyright holder for this preprint (which was not certified by peer review) is the author/funder, who has granted bioRxiv a license to display the preprint in perpetuity. It is made available under aCC-BY-ND 4.0 International license.

\section{*Corresponding Author Address}

\section{KelmaniChandrakanth.R}

Professor,

Department of Biotechnology,

Gulbarga University,

Kalaburagi- 584112, Karnataka-India

Email.ckelmani@gmail.com

Mobile.No. +919449439340. 


\begin{abstract}
The antibiotic resistance of an organism has become an endeavor worldwide. The resistance of bacteria is impacting the immunocompromised patient, especially with diabetic. The bacteriophages are more specific in the elimination of the infections caused by the organism. One of the significant bacteria is Vancomycin-resistant Enterococcus faecalis (VREF), emerging as bioburden rendering infectious diseases in developing countries. We attempted to treat infection of VREF in the induced and non -induced diabetic mice model along with antibiotic and phage treatment. The phage has shown more efficiency than vancomycin antibiotic alone and combined therapy with antibiotic phage treated. The considering phage therapy an alternative source for the treatment in the insulin-dependent diabetic with an infection of bacteria.
\end{abstract}

Keywords: Enterococcus faecalis, VREF, Phage therapy, Diabetic and Non-diabetic, drugresistant. 


\section{Introduction}

Enterococcus feacalis, a gram-positive facultative anaerobic bacterium, is mainly present in humans and animals' microbiota. It has now emerged as one of the significant causes of human clinical infections. Antibiotics are the 'miracle drugs used for treating bacterial infections. Due to the cheaper availability, these are commonly used and widely spread worldwide, leading to irrational uncontrolled uses of antibiotics, causing bacterial resistance[1,2]. Antimicrobial resistance is threatening to human health. It is one of the most significant challenges of our civilization. It could be possible to cause an estimated 10 million mortalities per year by 2050[3]. Glycopeptide antibiotic-resistant enterococci have become a significant threat to hospitalized patients causing breaks that increase morbidity, mortality, and health care [4]. Enterococci can acquire resistance to multiple antimicrobial agents rapidly totheir pathogen via transposons and plasmids [5, 6, 7]. The emergence of VRE is becoming a grave public health concern, especially in developing countries where there is a lack of availability of effective antibiotics[8]. The natural predators of bacteria are bacterial viruses known as bacteriophages or phages. These are ubiquitously found and are estimated to be present at numbers equivalent to a trillion per grain of sand on earth[9]. The bacteriophages can be an alternative potential antibacterial therapeutic agents against multidrug-resistant pathogens[10]. Phage therapy is rapidly evolving in medicinal uses in life-saving and undergoing multiple clinical trials. The present study checks bacteriophage therapy's efficacy against vancomycin-resistant Enterococcus feacalis in diabetic and non-diabetic induced mice models. 


\section{Material and Methods}

\section{Isolation of Bacteriophages}

E. faecalis specific bacteriophage was isolated by a regular enrichment procedure consistent with Sheng [11] from raw sewage collected from a municipal sewage treatment system. Briefly, 50-ml sewage samples were centrifuged at 5,000 rpm for $10 \mathrm{~min}$ at $4^{\circ} \mathrm{C}$. The supernatants were filtered through a $0.45 \mu \mathrm{m}$ - pore-size filter (Pall Life Sciences), $10 \mathrm{ml}$ filtrate was added to $1 \mathrm{ml} 10 \mathrm{X} \mathrm{LB}$ broth, and $100 \mu \mathrm{l}\left(\sim 10^{8} \mathrm{CFU}\right)$ of each E.faecalisstrain was added. The mixture was incubated at $37^{\circ} \mathrm{C}$ for $18 \mathrm{~h}$ with aeration $(180 \mathrm{rpm})$. Debris and bacteria were removed by centrifugation at $10,000 \mathrm{rpm}$ for $10 \mathrm{~min}$, and supernatants were filtered through a $0.2 \mu \mathrm{m}$-pore size filter (Pall Life Sciences). Phage activity within the supernatant was tested by a spot assay that entailed placing $5 \mu \mathrm{l}$ of the supernatant on BHI agar seeded with E. faecalis strains. The plates were evaluated for plaques formation after $18 \mathrm{~h}$ at $37^{\circ} \mathrm{C}$. Lysispositive supernatants were serially diluted, and plaques were isolated and purified, employing a soft agar technique.

\section{Broth Culture of Phage}

E. faecalis 122 was inoculated 1:100 ratio of $200 \mathrm{ml}$ of $\mathrm{BHI}$ broth and incubated at $37^{\circ} \mathrm{C}$ in a shaking incubator $(240 \mathrm{rpm})$. As the optical density OD at $600 \mathrm{~nm}$ showed 0.1 reading bacteriophage with $10^{7}$ plaque-forming unit $(\mathrm{PFU}) / \mathrm{ml}$, is then added to the cultured bacterial flask. Every $15 \mathrm{~min}$, samples were collected from the broth, and OD readings of infected and uninfected cells were measured at $600 \mathrm{~nm}$. Completely lysed cultures were then centrifuged $\left(10,000 \mathrm{rpm}, 5 \mathrm{~min}, 20^{\circ} \mathrm{C}\right)$, and chloroform-treated phage was titrated within the supernatant. 


\section{Adsorption rate, latent period, and phage burst size}

The procedure was carried according to the previous study by Adams [12]. Briefly, to check live the adsorption rate, $1 \mathrm{ml}$ phage $\left(1.5 \times 10^{3} \mathrm{PFU} / \mathrm{ml}\right)$ and $1 \mathrm{ml}$ VREF122 $\left(5 \times 10^{8}\right.$ $\mathrm{CFU} / \mathrm{ml}$ ) were mixed, and the number of free phage particles was resolute after treatment with chloroform $(200 \mu 1)$. To confirm the latent period and burst size, VREFbacteria $\left(5 \times 10^{8} \mathrm{CFU} / \mathrm{ml}\right)$ were incubated with phage $\left(3 \times 10^{3} \mathrm{PFU} / \mathrm{ml}\right)$ for five mins, washed with cold LB broth to get rid of free phage particles, and so resuspended in fresh medium. The cell suspension was periodically titrated for newly produced phage on the VREF122 culture lawn.

\section{Phage purification and Storage}

Theisolated colony of VREF122 was inoculated into BHI broth. Culture with OD of 0.1 is used to infect with phage GACP $2 \times 10^{7} \mathrm{PFU}$; the culture was co-cultivated for $18 \mathrm{~h} 37^{\circ} \mathrm{C}$ in a shaking incubator (240 rpm). Polyethylene glycol-8000(PEG) or $\mathrm{NaCl}$ was added to the lysate to a final concentration of $20 \%$ or $0.5 \mathrm{M}$ respectively and incubated for $1 \mathrm{~h}$ at $4^{\circ} \mathrm{C}$. After centrifugation at $10,000 \mathrm{rpm}\left(16 \mathrm{~min}\right.$ at $\left.4{ }^{\circ} \mathrm{C}\right)$ in the centrifuge, polyethylene glycol (PEG 8000) was added to the supernatant to a final concentration of $10 \%$. The lysate was incubated overnight at $4{ }^{\circ} \mathrm{C}$ with gentle stirring. Polyethylene glycol-precipitated phages were collected by centrifugation at 15,000 rpm for $20 \mathrm{~min}$. The resulting pellets were suspended in $3 \mathrm{ml}$ of phage buffer (20mM Tris-HCL [pH 7.4], 100mM NaCl, $10 \mathrm{mM} \mathrm{MgSo}$ ), filtered through $0.2 \mu \mathrm{m}$ bacterial filters, and phage filtrate was recovered and dialyzed against phage buffer. Purified phage GACP was stored in aliquots of phage buffer at $-20^{\circ} \mathrm{C}[13]$. 


\section{Electron Microscopy of Phage GACP}

A drop of the phage GACP suspension is applied to a formvar carbon-coated copper grid for five mins; the rest was removed with a pipette and negatively stained with $2 \%$ uranyl acetate (TAAB Laboratory UK). After $10 \mathrm{~min}$, the liquid is removed withpaper. The grids were examined in an exceedingly TechaniBiotwin (Philips), transmission microscope, (Netherland) at 80 Kv (Magnification, X105, 000 or X160, 000) [14].

\section{Animals Experiments}

\section{Animals}

Specific pathogen-free, colony bred, virgin adult Swiss mice (Wistar strain) of both sexes weighing $25 \pm 0.8$ grams were obtained from the experimental animal facility of Luqman College of pharmacy. Animals were used with the Institute Animals Ethics Committee (Reg.No. 346/CPSCEA). Animals are fed with pellets (VRK Nutrition Solutions, Sangli, Maharashtra, India Ltd.,) and water adlibitum. After randomization into groups and experiment initiation, the mice were acclimatized for seven days under standard laboratory conditions of temperature 24$28^{\circ} \mathrm{C}$, ratio humidity of $60-70 \%$, and $12 \mathrm{~h}$ day and night cycles). Mice were randomly assigned to groups were housed (in Luqman Pharmacy College's animal house at Kalaburagi) in cages of two or three until experiments started.

\section{Preparation of Streptozotocin (STZ) doses}

Mice were made diabetic by consequent intraperitoneal injections of various concentrations of STZ (Hi media, Mumbai). STZ was first weighed individually for every animal 
per the weight and so suspended in $0.2 \mathrm{ml}$ citrate buffer ( $0.1 \mathrm{M}$ Citrate buffer, $\mathrm{pH} 4.5)$ just before injection.

\section{STZ-induced Diabetes}

To induce diabetes, the mice were treated with STZ [60, 120, and $180 \mathrm{mg}$ (Kg body weight $^{-1}$ in $0.1 \mathrm{M}$ Citrate Buffer, $\mathrm{pH} 4.5$ ] by intraperitoneal administration for 3 consecutive days. At the time of the STZ injection, the mice are fasted for 14-16 h but had free access to water. After the STZ treatment, all the mice were returned to their cages and given free access to food and water. Blood sugar levels are monitored after the stabilization period of ten days [15].

\section{Collection of blood from Experimental mice}

The mice are weighed weekly, and blood glucose levels are determined to assess hyperglycemia employing a handheld glucometer. Blood samples were collected from the tail vein, and also the fasting blood sugar levels were estimated using an Acu-Check Active (Indiapoils) electronic glucometer.

\section{Pathogen}

The pathogenic strain of VREF 122 (Catalase negative, MDR, high-level resistant vancomycin, mouse virulent) was employed in all experiments. This organism was grown in BHI broth was to prepare bacterial inocula. To induce infection in mice, $10^{6}-10^{9} \mathrm{CFU} / \mathrm{ml}$ count of $E$. faecalis washed in $0.2 \mathrm{ml}$ of $0.9 \%$ PBS was used.

\section{Experimental induction of VREF122 bacteremia in Diabetic and non-diabetic mice}

For each infection experiment, 6 to 8-week old diabetic and non-diabetic mice were divided into two groups, and each group was given inocula of varied sizes. Preparation of the 
infecting bacteria was as follows, VREF122 isolate was grown in the $\mathrm{BHI}$ broth medium at $37^{\circ} \mathrm{C}$ and centrifuged at $8,000 \mathrm{rpm}$ for five mins. The cell pellet was washed with normal PBS, centrifuged again under identical conditions, and at last resuspended in $10 \mathrm{ml}$ PBS. After appropriate dilution, turbidity at $600 \mathrm{~nm}$ is measured to see bacterial cell numbers. To evaluate minimum lethal dose (MLD), serial dilutions of VREF122 were injected intraperitoneally (i.p.) into diabetic and non-diabetic mice in $0.1 \mathrm{ml}$ aliquots. After infection, mice are kept under standard laboratory conditions with free access to food and water. Twelve mice were used for each dose; non-diabetic and diabetic mice's survivals were then measured two days postinfection [16]. Mice inoculated with VREF122 were observed for their state of bacteremia. They were scored for their state of health on anarbitrary scale of 5 to 0 , supported by progressive disease state reflected by several clinical signs. An unremarkable condition is scored as 5, slight illness, defined as lethargy and ruffled fur, is scored as 4, moderate disease, characterized as severe lethargy, ruffled fur, and hunched back, is scored as 3; severe illness, with the above signs plus exudative accumulation around partially closed eyes, is scored as 2, a moribund state is scored as 1 , and death is scored as 0 . The dose which shows $50 \%$ lethality is taken because of the optimum $\mathrm{LD}_{50}$ dose.

\section{Detection of Pathogen in Circulatory System}

An experiment to determine the entry of VREF122 infection in mice from the peritoneal cavity into the circulatory system is executed. The bacteria were injected i.p. followed by the gathering of blood samples from the tail vein, and approximately $0.1 \mathrm{ml}$ was collected into a 1.5 ml E-tube containing $10 \mu \mathrm{l}$ EDTA $(100 \mathrm{mM})$. The blood samples obtained were cultured on bile esculinazide agar. 


\section{Vancomycin Treatment in VREF122infected mice}

The animals were divided into four groups, two of diabetic and non-diabetic, followed by induction of VREF122 strain. One group was kept as the control without antibiotic induction, and the remaining were injected with the antibiotic of vancomycin $[2 \mathrm{mg}(\mathrm{Kg} \text { body weight })]^{-1}$ after 20 min of pathogen administration. Further, the antibiotic was routinely induced for five days.[17].

\section{Efficacy of phage GACP in bacteremia mice model}

The phage's efficacy was studied in six groups of mice (Twelve mice in each group) and was challenged by the intraperitoneal injection of VREF122. Each group was treated with a single injection of GACP at $3 \times 10^{10} \mathrm{PFU}$ after $20 \mathrm{~min}$ of bacterial induction. The experiment is observed for 30 days.

\section{Combined therapy in bacteremia mice model}

The combined therapeutic potential is determined usingvancomycin antibiotic and phage GACP in diabetic and non- diabetic VREF122bacteremia mice model. The effect of antibiotic and phage dose is studied within the six groups of mice (Twelve mice in each group). A single dose of Vancomycin antibiotic was administered i.p after 20 min bacterial induction and followed by phage with a dose of $3 \times 10^{11} \mathrm{PFU}$.

\section{Quantification of the immunological reaction of phage GACP in mice}

Bacteriophages are beneficial agents for studies of humoral immunity. They are potent antigens that cause no toxic effect on the health of humans. [18, 19]. 
During the experiment of mice were treated with phage GACP $\left(3 \times 10^{10} \mathrm{PFU}\right)$ through i.p injection. At various time points, mice blood was collected from the optic vein and cultured. Subsequently, the collected blood was subjected to indirect Enzyme-Linked Immunosorbent Assay to detect antibodytiters of $\operatorname{IgG} \operatorname{IgM}$ antibody titers in sera of diabetic and non-diabetic mice as described [20]. 


\section{Results:}

\section{Bacteriophage isolation}

The MDR strains of E.faecalis were inoculated with sewage samples obtained from different local drainages. And supplements were harvested, and it is subjected to the spot test. The spot test for phage formed a clear zone on a specific number of the E.faecalis isolates. Among them, VREF 122 isolate tested manifested turbid zone is shown in figure results indicates that the phage possessed a lytic nature against an isolate of VREF 122

. The adsorption rate, latent period, and burst size of phage thought to be biological parameters for phage infection measurements are shown in the figure.Comparing these parameters of $\phi \mathrm{GACP}$, the adsorption rate within 5 min was about $90 \%$, the latent period was about 25min, the burst size was about 110-120 PFU/cell. Medians of latent period and burst size in tailed phage were typically 40-60min and 50-100 PFU/cell, respectively, and were capable of infecting a large spectrum ofE. faecalis strains, causing completed and confluent lysis. Thus, it was indicated that $\phi \mathrm{GACP}$ as a therapeutic agent to manage infections caused by MDRE.faecalis, as shown in figure 2.

\section{Transmission electron microscope}

Phage GACP possesses isometric heads of $100 \mathrm{~nm}$ in diameter and conspicuous capsomers, striated 140 long tails, a double base plate, and globular structures at the tail tip, as shown in Figure.3. It belongs to thefamily myoviridae, subfamily Spounavirine family. The proposed subfamily contains the ICTV recognized genus "SPO1-like viruses." 


\section{Streptozotocin (STZ) - induced diabetes in Experimental Mice}

Mice induced with multiple doses of STZ [150 mg (Kg body weight)- ${ }^{1}$ ] have shown chronic hyperglycemia as represented in Table.1. One group received a dose of $180 \mathrm{mg}$ of STZ (Kg body weight)- ${ }^{1}$ died after 20 days. Groups of mice that received a concentration of $120 \mathrm{mg}$ of STZ (Kg body weight) $-{ }^{1}$ were healthy and alive for two months. Although the diabetic mice exhibited glycosuria, they also developed ruffled hair, appeared thinner, and consumed more food per day than the untreated group. The glucose level $\geq$ of $300 \mathrm{mg} / \mathrm{dl}$ was considered as diabetic mice.

Host screening of Vancomycin-resistant E.faecalis strain in diabetic and non-diabetic mice.

A total of 12 VREF strain VREF 122 were selected based on its high resistant and multidrug-resistant nature and its susceptibility for phage GACP lytic multiplication. Finally, bacterial strain VREF 122 is set for induction of bacteremia in diabetic and non-diabetic mice.

\section{Induction of experimental bacteremia in diabetic and non-diabetic mice model with VREF}

\section{2 isolate}

The lethal dose of E. faecalis to mice was resolute by injecting both diabetic and nondiabetic mice with varying cell concentration VREF122, starting from $3 \times 10^{6}$ to $3 \times 10^{9}$ cells $/$ dose. Intraperitoneal injection of $3 \times 10^{6}$ to $3 \times 10^{7}$ didn'tdecrease the persistence rate of diabetic, whereas 10 to 20 percent of mice died during the next seven day observation period and 0 to 20 percent non-diabetic mice, respectively. In contrast, VREF122 $3 \times 10^{8}$ cells showed a survival rate of 50 percent in diabetic and non-diabetic mice within $48 \mathrm{hrs}$. VREF 122, 3x10 ${ }^{8}$ showed a 100\% lethal effect within $48 \mathrm{~h}$ of injection in both groups of animals as shown in Figure $4 \mathrm{a}$ and b; therefore, this dose $3 \times 10^{8} \mathrm{CFU} / \mathrm{ml}$ was the optimal dose for the experiment. 


\section{Protection of lethal bacteremic diabetic and non-diabetic mice by $\phi$ GACP}

Different concentrations ofpurified phage GACP of $3 \times 10^{7}$ to $3 \times 10^{10} \mathrm{PFU}$ were injected to check the protection activity in diabetic and non-diabetic mice from VREF 122 of lethal bacteremia. Figure $5 \mathrm{a}$ and $\mathrm{b}$ show that $3 \times 10^{10}$ of $\phi$ GACP significantly rescued $100 \%$ diabetic and non-diabetic mice from fatal bacteremia. All live mice remained healthy for 30 days till the experiment was terminated. The phage dose effect on the health status of the infected animals was visible. Administration of a high dose $3 \times 10^{10}$ of phage GACP alone to experimental mice also didn't affect their soundness of survival of mice during the one month of observation.

\section{Treatment efficacy of phage compared withvancomycin antibiotic in diabetic and non- diabetic mice}

Phage's effectiveness with vancomycin, antibiotic treatment of diabetic and non-diabetic mice, a single i.p. dose of vancomycin $\left[2 \mathrm{mg}(\mathrm{Kg}\right.$ body weight $\left.)-{ }^{1}\right]$ after $20 \mathrm{~min}$ of VREF 122 results exhibited $70 \%$ protection in both diabetic and non diabetic mice from VREF122. Whereas, phage GACP of $3 \times 10^{10} \mathrm{PFU}$ has rescued $100 \%$ in both mice groups from VREF 122 bacteremia. There have been no survivors among untreated mice (in both groups) after two days of i.p injection $3 \times 10^{8}$ CFU cells of VREF122 as shown in (Fig.5a \& b). The protected mice were healthy for the next seven days of observation time.

Protection of lethal bacteremia mice by combined treatment with $\phi$ GACP and Vancomycin antibiotic 
A purified $\phi$ GACP of $3 \times 10^{7}$ to $3 \times 10^{10} \mathrm{PFU}$ and a single dose of $[2 \mathrm{mg}(\mathrm{Kg}$ body weight $)-$

${ }^{1}$ ] vancomycin induced showed the protection efficiency of $80 \%$ and $90 \%$ in diabetic and nondiabetic mice from VREF122 induced lethal bacteremia. All live mice remained healthy for additional 30 days of observation when the experiment was terminated. The phage dose effect on the state of health of the infected animals was visible, as shown in Fig.5a and b. The survival of the mice was observed for one month.

\section{Study of the immune response against $\phi$ GACP in diabetic and non diabetic mice}

The blood was collected from the optical vein of mice, and serum was separated from both IgG and IgM titers of anti-phaged GACPantibodies were detected subsequently with 3000fold and 500-fold, respectively groups. The anaphylactic reactions that appeared are adverse and detected no significant differences in core body temperatures or other disastrous events. 


\section{Discussion}

The bacteriophages are highly specific for the target bacteria without affecting the normal micro-flora, are effective against multiple drug resistant bacteria. However, phages were discovered nearly a century ago [21]. Western medicine's interest in them as therapeutic agents was relatively short-lived because of the eventual discovery and instant success of antibiotics and in part because of the highly empirical and counterproductive approach used by phage practitioners in the early era. In the modern era 1980s and 1990s, some rigorously controlled animal experiments have been conducted animal experiments have been $[\mathbf{7 , 2 2}]$, .but the clinical reports in this same era have been subjective rather than unfolding controlled studies [23].

The present study emphasized the isolation of MDR strains of E.faecalis, inoculated with sewage samples obtained from different local drainages, and phage were harvested and then subjected to the spot test. In the spot test, phage formed a clear zone on E.faecalis VREF 122. The results possessed a lytic nature against isolates of E.faecalis 122 as positive. In study conduct, the phage strain isolated ENB6 was found to form plaques on 57\% of the VRE clinical isolates, and it inhibited bacterial growth of an additional $22 \%$ of the strains, exhibiting an antibacterial effect against $79 \%$ of the strains in collected samples[20]. Further reports on phage Ф SH-56 forming plaques on more than $79 \%$ of the MDR enterococci isolates tested and inhibits $7 \%$ growth, thus providing an antibacterial effect against more than $86 \%$ of approximately 32 clinical isolates of MDR enterococci isolated from diabetic foot cases has been reported [24].

In a study, the one-step growth curve is carried out to identify the different phases of the phage infection process. The phage $\Phi$ AB2 adsorbed efficiently had a short latent period and caused complete lysis. Upon infection of A. baumannii ATCC 17978 in the early- exponential 
phase $\left(\mathrm{OD}_{600}=0.6\right)$ with $\Phi \mathrm{AB} 2$ at an MOI of 0.001 , cultures were cleared $2 \times 10^{10} \mathrm{PFU} / \mathrm{ml}$ of progeny was obtained [25]. The adsorption rates $\Phi$ AB2 to the A. baumannii ATCC 17978 cells showed approximately $75 \%$ of phage particles absorbed to host cells within 2 mins, $95 \%$ in 4 min, and nearly $100 \%$ in 10 mins. In the tube lysis test, the stool phages JS4 and JS94.1, the environmental water phages JSD.1, and JSL.6 showed a complementary lytic potential of pathogenic E. coli strain collected. The tested K803 strain, progeny phage was detected in broth culture infections at about 40 min post-infection, and phage titer increased later, sometimes in a biphasic way [26].

Our study of phage $\phi$ GACP has shown the biological parameters' measurements as adsorption rate, latent period, and burst size. Comparing these parameters of $\phi$ GACP, the adsorption rate within 5 min was about $90 \%$, the latent period was about $25 \mathrm{~min}$ and the burst size was about $110-120$ and an average burst size $5 \times 10^{8} \mathrm{PFU} / \mathrm{ml}$. As medians of latent period and burst size in tailed phage are typically 40-60min and 50-100, respectively and was capable of infecting a broad spectrum of E. faecalis strains, causing completed and confluent lysis, indicating that $\phi$ GACP as a therapeutic agent to control infections caused by MDR E.faecalis.A study on phage 4D against E. faecalis showedlatent period, and burst size for tailed phages is usually 40-60 min and 50-100. A one-step growth curve for $44 \mathrm{D}$ showed a latent period (defined as the time interval between the adsorption and the beginning of the first burst) of about $25 \mathrm{~min}$ and an average burst size of about $36 \mathrm{PFU} / \mathrm{cell}[27]$.

Transmission electron microscopy (TEM) of phage $\phi 4 \mathrm{D}$ revealed an isometric head and a contractile tail with a baseplate. The tubular rear was $164 \pm 4.5 \mathrm{~nm}$ in length, and the head was $74 \pm 4 \mathrm{~nm}$ in diameter [27]. According to Ackermann's classification, $\phi 4 \mathrm{D}$ was assigned to the Myoviridae family based on these morphological characteristics. A study on E. faecalisфSH-56 
confirmed the presence of an icosahedral head, about $65 \mathrm{~nm}$ in diameter, and a $100 \mathrm{~nm}$ long tail, morphologically like phages belonging to Siphoviridae[23]. This study of $\phi$ GACP reveals that it possesses isometric heads of $100 \mathrm{~nm}$ in diameter and conspicuous capsomers, striated 140 long tails, a double base plate, and globular structures at the tail tip of family myoviridae, subfamily Spounavirine family. Phage ENB6 of vancomycin-resistant E.faecium has shown a moderately elongated head, $99.7 \mathrm{~nm}$ long and $84.4 \mathrm{~nm}$ wide, and a contractile tail (199.1 nm long). The phage is of the A2morphotype[28], as observed by negative staining with uranyl acetate.

Many sepsis mouse models are typically used to assess phage therapy against nosocomial bacteria $[20,28,24,29]$. In a study to examine therapeutic effectiveness and the effect of host sensitivity difference on the phage in-vivo,E. faecalis sepsis mouse models using BALB/c mice were set up using two strains, EF14 and VRE2. EF14 had phage sensitivity about 32 times greater than that of VRE2 (efficiency of plating [EOP] against EF14, 1; EOP against VRE2, 0.032)[30]. After intraperitoneal bacterial inoculation at different concentrations to mice, the minimum lethal bacterial dosage of EF14 and VRE2 was determined to be $1.0 \times 10^{10}$ and $4.2 \times$ $10^{9}$ bacteria; these dosages resulted in $100 \%$ lethality within 2 days. These bacterial dosages were used for our experiments to assess mouse rescue by phage. In diabetic mice, S.aureus infection with multiple doses of STZ [ $120 \mathrm{mg}(\mathrm{kg} \text { body weight })^{-1}$ ] is induced in the mouse model. STZ and fasting blood glucose levels after STZ treatment animals with blood glucose levels > $250 \mathrm{mg} / \mathrm{dl}$ were considered a diabetic model [31, 32]. The STZ diabetic model may serve as a better model since diabetes can be initiated at a younger age when all animals have reached maturity and with negligible weight loss $[33,34]$.

In our animal experiment, the mice were induced with $180 \mathrm{mg} / \mathrm{dl}$ with STZ to make diabetic, and the glucose level is maintained in the induced mice at 300mg/dl. The lethal dose of 
E. faecalis VREF122 to mice was determined by injecting $3 \times 10^{8}$, diabetic and non-diabetic mice.

In the study reported by Biswas et al., vancomycin resistant E. faecium bacteremia with MLD $10^{9} \mathrm{CFU}$ when inoculated was found to be fatal within $48 \mathrm{~h}[20]$, thus $3 \times 10^{9} \mathrm{CFU}$ as used for the further experiment in our study.

A study on therapeutic effectiveness in vivo of $\Phi$ EF24C observed no abnormal mouse behavior or altered survival rate following administration of saline or phage alone $\left(1.0 \times 10^{12}\right.$ PFU); thus, the phage rescue experiments were considered to be conducted without bias [30]. The dose-dependent effectiveness is observed to be less than MOI of 0.01 and 0.1 of EF14 and VRE2 mouse sepsis models, respectively, and was similar to results of $\Phi$ EF24C efficiently rescuing mice infected with both EF14 and VRE2 at an MOI of 0.01. In the present study single dose of $\phi$ GACP $3 \times 10^{10}$ PFU was applied intraperitoneally (i.p) after 20 min VREF 122 challenge and showed significant rescue of $100 \%$ in both diabetic and non-diabetic mice from lethal bacteremia. Biswas et al. showed the phage ENB6 9x109 single dose was administrated i.p 45 min after the challenge with the MLD of bacteria. By 24 h dose effect on the state of health of the infected animals was visible. At higher doses of phage multiplicities of infection of 0.3 and 3.0, 100\% of the animals survived, and only minimal signs of illness were observed [20].

To analyzed phage treatment safety with the chemotherapeutic treatment of diabetic and non-diabetic single of single i.p dose of vancomycin [2mg (Kg body weight) ${ }^{-1}$ showed $70 \%$ percent protection in both groups.If there is an antagonistic effect, the mice no demonstrated changes with the comparable grouping of phage and antibiotic induction. A comparative investigation has been reported [31]. These outcomes additionally concur with prior studies[17, 35, 36], in which a stamped distinction in the impact of phage treatment was in bunches 
rewarded with bacteriophages contrasted with antibiotics agents.Anyway, no investigations have been accounted for E. feacalis in induced and non induced diabetic mice.

There is an accord that the general condition of the Slopek and KucharewicaKrukowska[20] animal or patient at the beginning of phage therapy affects the patient's immunity. In the present study, $\operatorname{IgG}$ and $\operatorname{IgM}$ were estimated in diabetic and non-diabetic following 28 days of single dose injection of $\phi$ GACP, increased in the titer background by 3000 fold and 500 fold respectively in both groups. No critical distinction was found among diabetic and non-diabetic IgG and IgM titers against ф GACP. No anaphylactic reactions, changes in core body temperature, or other adverse events were observed in the two groups. In an immune response study of phage ENB6 against CRMEN 44 VRE strain, IgG and IgM levels raised against the phage expanded above 3,800-fold and 5-fold, respectively. Anaphylactic reactions were negative, and no changes in core body temperature or other adverse events were observed in the mice for the multiple injections of phage [20].Similar findings were reported for patients with severe combined immune deficiency (SCID) described by poor or undeveloped detectable antibody responses to phages even after repeated injections[18, 37].

\section{Disclosure Statement}

No conflict of interest from all the authors. 


\section{References:}

1. ManoharP, Shanthini T, Ayyanar R, Bozdogan B, Wilson A, TamhankarAJ, Nachimuthu R, Lopes BS. The distribution of carbapenem-and colistin-resistance in gram-negative bacteria from the Tamil Nadu region in India. J Med Microbio.2017;20: 66(7):874-83.

2. LuepkeKH, Suda KJ, Boucher H, RussoRL,Bonney MW, Hunt TD, Mohr JF. Past, present, and future of antibacterial economics: increasing bacterial resistance, limited antibiotic pipeline, and societal implications. Pharmacother. J Hum Pharmacol Drug Ther.2017; 37(1):71-84.

3. O'Neill J. Tackling Drug-Resistant Infections Globally: Final Report and Recommendations. The Review on Antimicrobial Resistance.2016; 1-76.

4. Hospital Infection Control Practices Advisory Committee. Recommendations for preventing the spread of vancomycin resistance: recommendation of the Hospital Infection Control Practices Advisory Committee (HICPAC). Am J Infect Control. $1995 ; 23(2): 87-94$.

5. European Center for Disease Prevention and Control. Data from the ECDC Surveillance Atlas Antimicrobial resistance (2017). https://ecdc.europa.eu/en/antimicrobial-resistance / surveillance-and-disease-data/data-ecdc. Accessed 05 Nov 2017.

6. Pinholt M, Gumpert H, Bayliss S, Nielsen JB, Vorobieva V, Pedersen M,Feil E, Worning P, Westh H.Genomic analysis of 495 vancomycin-resistant Enterococcus faeciumreveals broad dissemination of a vanA plasmid in more than 19 clones from Copenhagen, Denmark. J Antimicrob Chemother.2017; 72:40-7. 
7. BenderJK, Kalmbach A, Fleige C, Klare I, Fuchs S, Werner G. Population structure and acquisition of the VanB resistance determinant in German clinical isolates of Enterococcus faecium ST192. Sci Rep.2016;6:21847.

8. Seid Ali, Martha A, Mulat D and Teklay G. Vancomycin Resistant enterococci and its associated risk factors among HIV-Positive and Negative Clients Attending dessie referral hospital, Northeast Ethiopia. International Journal of Microbiology.2018; 1-9.

9. Keen EC. A century of phage research: bacteriophages and the shaping of modern biology. Bio-essays.2015; 37 6-9.

10. Burrowes B, Harper, DR, Anderson J, Mcconville M, and Enright MC. Bacteriophage therapy: potential uses in the control of antibiotic-resistant pathogens. Expert Rev. Anti. Infect. Ther.2011;9, 775-785.

11. Sheng H, Knecht HJ, Kudva IT, Hovde CJ.Application of bacteriophages to control intestinal Escherichia coli 0157:H7 levels in ruminants. Appl. Environ. Microbiol.2006; 72:5359-5366.

12. Adam MH.Assay of phage by agar layer method.In: Bacteriophages.Interscience Publishers, Inc. New York, 1959; 450-454.

13. Uchiyama J,RashelM,Meda Y, Takemura I, Sugihara S, Akechi K, Muraoka A, Wakiguchi $\mathrm{H}$ and Matsuzaki S. Isolation and characterization of a novel Enterococcus faecalis Bacteriophage $\Phi E F 24 \mathrm{C}$ as a candidate therapeutic. FEMS Microbiol. Lett. 2007;278:200-206.

14. Karam JD.Molecular biology of Bacteriophage T4. ASM Press, Washington.D.C1994. 
15. Carvalho EN, Carvalho NS, Ferreira LM. Experimental model of induction of diabetes mellitus in rats. Acta Cir. Bras. 2003; 18 Special Editions.

16. Merril CR, Biswas B, Carlton R, Jensen NC, Creed GJ, Zullo S and Adhya S. Longcirculating bacteriophage as antibacterial agents. Proceedings of the NationalAcademy of Sciences of the United States of America. 1996;93: 3188-3192.

17. Smith HW and Huggins MB. Successful treatment of experimental Escherichia coli infections in mice using phage: its general superiority over antibiotics. J. Gen. Microbiol. $1982 ; 128: 307-318$.

18. Ochs HD,Davis DS, Wedgwood JR.Immunologic responses to Bacteriophage FX174 in immunodeficiency diseases. Clin. Investig. 1971;50:2559-2568.

19. De la Cruz VF, Lal AA, McCutchan TF. Immunogenicity and epitope mapping of foreign sequences via genetically engineered filamentous phage. J Biol. Chem. 1988;263(9):4318-22.

20. Biswaji B, Sankar A, Paul W, Brain P, Anderi NT, Bradford P, Richard C and Carl RM. Bacteriophage therapy rescues mice bacteremic from a clinical isolate of vancomycin resistant Enterococcusfaecium. Infect Immun. 2002;70(1):204-210.

21. Bojovazova CG, Voroshilasova NN,Bondarenko VM. The efficacy of Klebsiella Bacteriophage in the therapy of experimental Klebsiella infection. J. Microbiol Epidemiol Immunobiol. 1991; 4:5-8.

22. SoothillJS (1994). Bacteriophage prevents destruction of skin grafts by Klebsiellasps.Burn. 1994;20:209-11. 
23. Vinodkumar CS,Makari HK, Srinivasa H,Basavarajappa KG,Kalsurmath S. Bacteriophage therapy: A potential use of phages in medical field. Res Rev BioSci.2009;12:22-8.

24. Vinodkumar CS, Neelagund YF and Kalsurmath S.Bacteriophage in the treatment of experimental septicemic mice from a clinical isolate of multidrug resistant Klebsiellapneumoniae. J. Commun. Dis. 2005;37:18-29.

25. Nein TL, Pei YC, Kai CC, Li Kuang Chen, Meng JL.Isolation and Characterization of $\varphi \mathrm{AB} 2$ a novel bacteriophage of Acinetobacterbaumanni. Research in Microbiology. 2010;161 (4).308-314.

26. Sandra CC, Anne B, Marie LD and Harald B. Phage-Host Interaction: an Ecological Perspective. Journal of Bacteriology.2004; 3677-3686.

27. Ackermann HW, DuBow MS.Viruses of prokaryotes. I. General properties of bacteriophages. Boca Raton, FL: CRC Press.1987.

28. Matsuzaki S, Yasuda M, Nishikawa H, Kuroda M, Ujihara T, Shuin, T,Shen Y, Jin Z, Fujimoto S, Nasimuzzaman MD, Wakiguchi H, SugiharaS, Sugiura T, Koda S, Muraoka A and Imai S.Experimentalprotection of mice against lethal Staphylococcus aureus infection by novelbacteriophage phi MR11. J. Infect. Dis. 2003; 187:613-624.

29. Watanabe R, Matsumoto T, Sano G, Ishii Y, Tateda K, Sumiyama Y, Uchiyama J, Sakurai S,Matsuzaki S, Imai S and Yamaguchi K. Efficacy of bacteriophage therapy against gut-derived sepsis caused by Pseudomonas aeruginosa in mice. Antimicrob. Agents Chemother.2007;51:446-452.

30. Uchiyama J,Rashel M,Meda Y, Takemura I, Sugihara S, Akechi K, Muraoka A, Wakiguchi $\mathrm{H}$ and Matsuzaki S. Isolation and characterization of a novel Enterococcus 
faecalis Bacteriophage $\Phi E F 24 C$ as a candidate therapeutic. FEMS Microbiol. Lett.2007; 278:200-206.

31. Raju S, Shirpad AP and Kelmani CR. Bacteriophage therapy for Staphylococcus aureus bacteremia in Streptozotocininduced diabetic mice. Res. Microbiol.2010; 161:854-860.

32. Nagaveni S, Rajeshwari H, Liyakat A, Ajay KO, Syed S, Shivshetty S, Patil SA, Chandrakanth RK . Experimental protection of diabetic mice against lethal P. aeruginosa infection by bacteriophage. BioMed Research International.2014; (3):739242.1-11.

33. Sun N, Yang G, Zhao H, Savelkoul,Huub, FJ,LiguoA. MultidoseStreptozotocin induction of diabetes in BALB/cMice induces a dominant oxidative macrophage and a conversion of TH 1 to TH 2 phenotypes during disease progression. Mediators Inflamm. 2005;1155: 202-209.

34. Shyh-Ming T, Cheng-chin H, Mei-Chin Y. Methicillin-resistant Staphylococcus aureus infection in diabetic mice enhanced inflammation and coagulation. J. Med. Microbiol.2006;55:379-385.

35. Slopek S, Weber DB, Dabrowski M, Kucharewicz KA. Results of Bacteriophage treatment of supportive bacterial infections in the years 1981-1986. Arch. Immunol.Ther.Exp. 1987; 35:569-583.

36. Levin B, Bull JJ. Phage therapy revisited: the population biology of a bacterial infection and its treatment with Bacteriophage and antibiotics.Am. Naturalist. 1996; 147. 881-898.

37. ClarkL, GreenbaumC, Jiang J, Lernmark A, Ochs H. The antibody response to Bacteriophage is linked to the lymphopenia gene in congenic Bio-Breeding rats. FEMS Immunol. Med. Microbiol. 2002; 32:205-209. 
Table.No.1.Fasting Blood Glucose Concentration in mice $(n=12)$ administered with various doses of Streptozotocin

\begin{tabular}{|c|ccc|}
\hline I.P doses of STZ $(\mathrm{mg} / \mathrm{Kg})$ & Fasting blood glucose $(\mathrm{mg} / \mathrm{dl})$ & at day after STZ administration \\
\cline { 2 - 4 } & Day 10 & Day 15 & Day 20 \\
\hline 0 & 83 & 89 & 96 \\
60 & 110 & 134 & 178 \\
120 & 272 & 356 & 422 \\
150 & 312 & 378 & 442 \\
180 & 372 & 484 & 558 \\
\hline
\end{tabular}




\section{List of Figure Legends}

Figure 1. Plate showing plaque formation of bacteriophage on BHI agar media against VREF122.

Figure 2. Lysis of Enterococcus faecalis EF122 isolate by the phage in broth culture.

A.OD development of an uninfected control culture (VREF122) and parallel Culture infected with Phage GACP

B. Progeny phage release from the phage infected culture depicted in fig $A$. Phage infectivity was measured by plaque assay.

Figure 3: TEM of phage GACP magnification X68, 000.

Figure 4: a. Determination of the Minimal Lethal Dose (MLD) of VREF122 in Diabetic mice $3 \times 10^{6}$ (A) 3x107 (B) $3 \times 10^{8}(\mathrm{C}) 3 \times 10^{9}$ (D), 1X PBS Control CFU/ml represents percentage of the survival rates up to 48 hours after administration.

b. Determination of the Minimal Lethal Dose (MLD) of VREF122 in Nondiabetic mice $1 \mathrm{X}$ PBS control,(A) $3 \times 10^{7}$ (B) $3 \times 10^{8}$ (C)3x10 ${ }^{9}$ (D) $\mathrm{CFU} / \mathrm{ml}$ represents percentage of the survival rates up to 48 hours after administration.

Figure 5: a Determination of the protection of VREF122 in Diabetic mice control PBS (A) $3 \times 10^{10}$ single dose of phage $(B)$ single dose of vancomycin antibiotic $(C) 3 \times 10^{10}$ phage and single dose of antibiotic represents percentage of the survival rates up to 7 days after administration.

b Determination of the protection of VREF122 in Non-Diabetic mice control PBS (A) $3 \times 10^{10}$ single dose of phage (B) single dose of vancomycin antibiotic (C) $3 \times 10^{10}$ phage and single dose of antibiotic represents percentage of the survival rates up to 7 days after administration. 


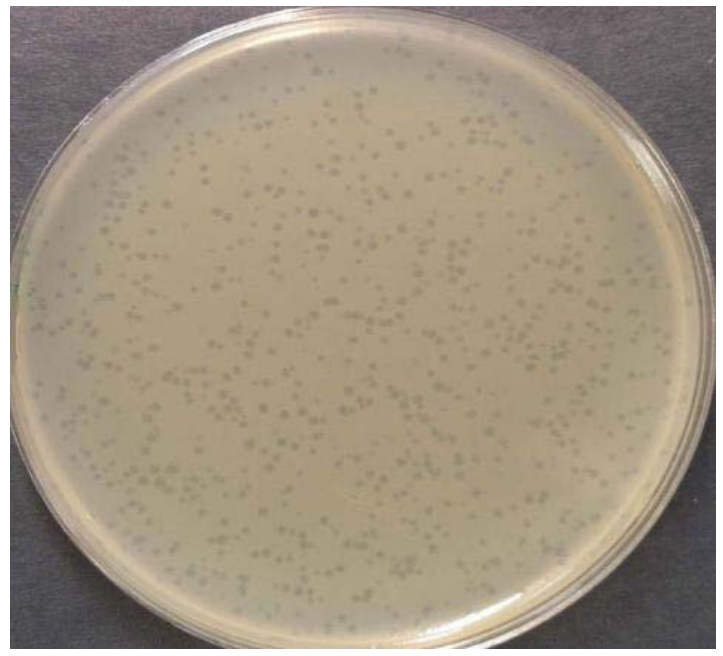

Figure.No.1.Plate showing plaque formation of bacteriophage on BHI agar media against VREF122.

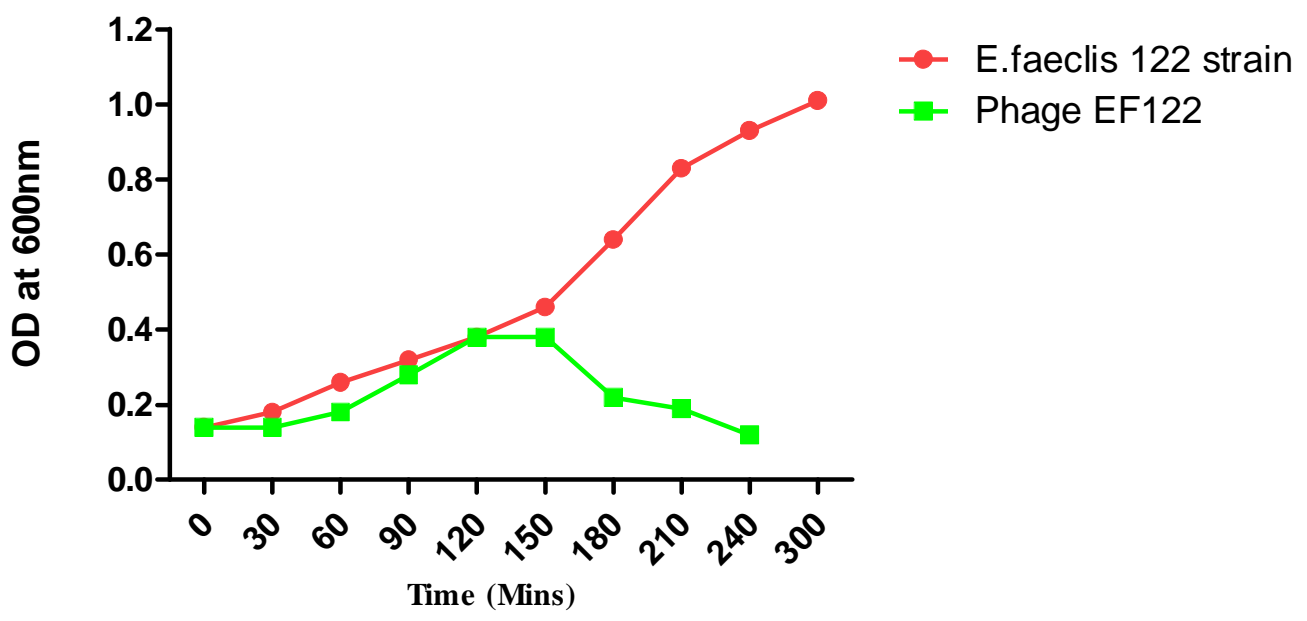

Figure. A 


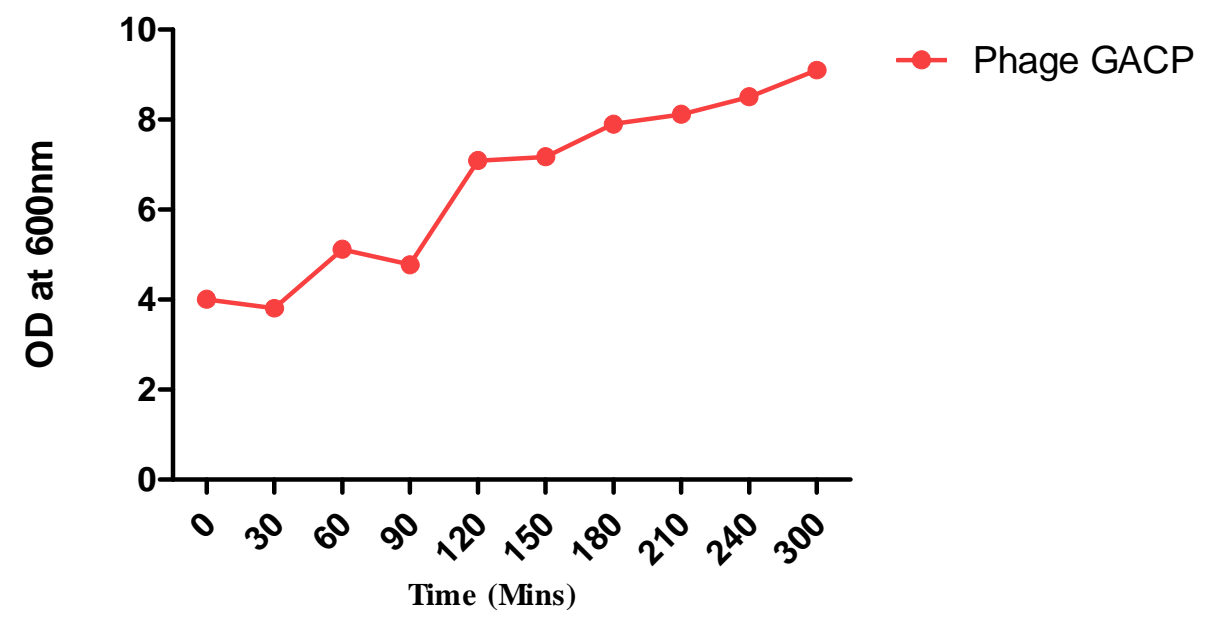

Figure. B

Figure 2:Lysis of Enterococcus faecalis EF122 isolate by the phage in broth culture.

A.OD development of an uninfected control culture (VREF122) and parallel culture infected with Phage GACP

B. Progeny phage release from the phage infected culture depicted in fig $A$. Phage infectivity was measured by plaque assay.

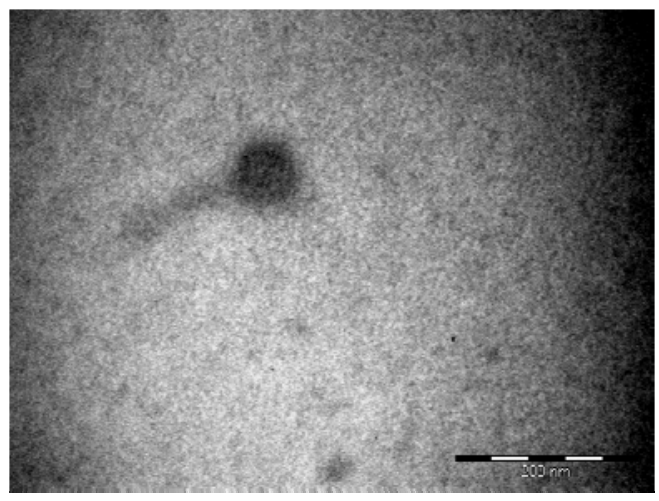

Figure.No.3TEM of phage GACP magnification X68, 000 


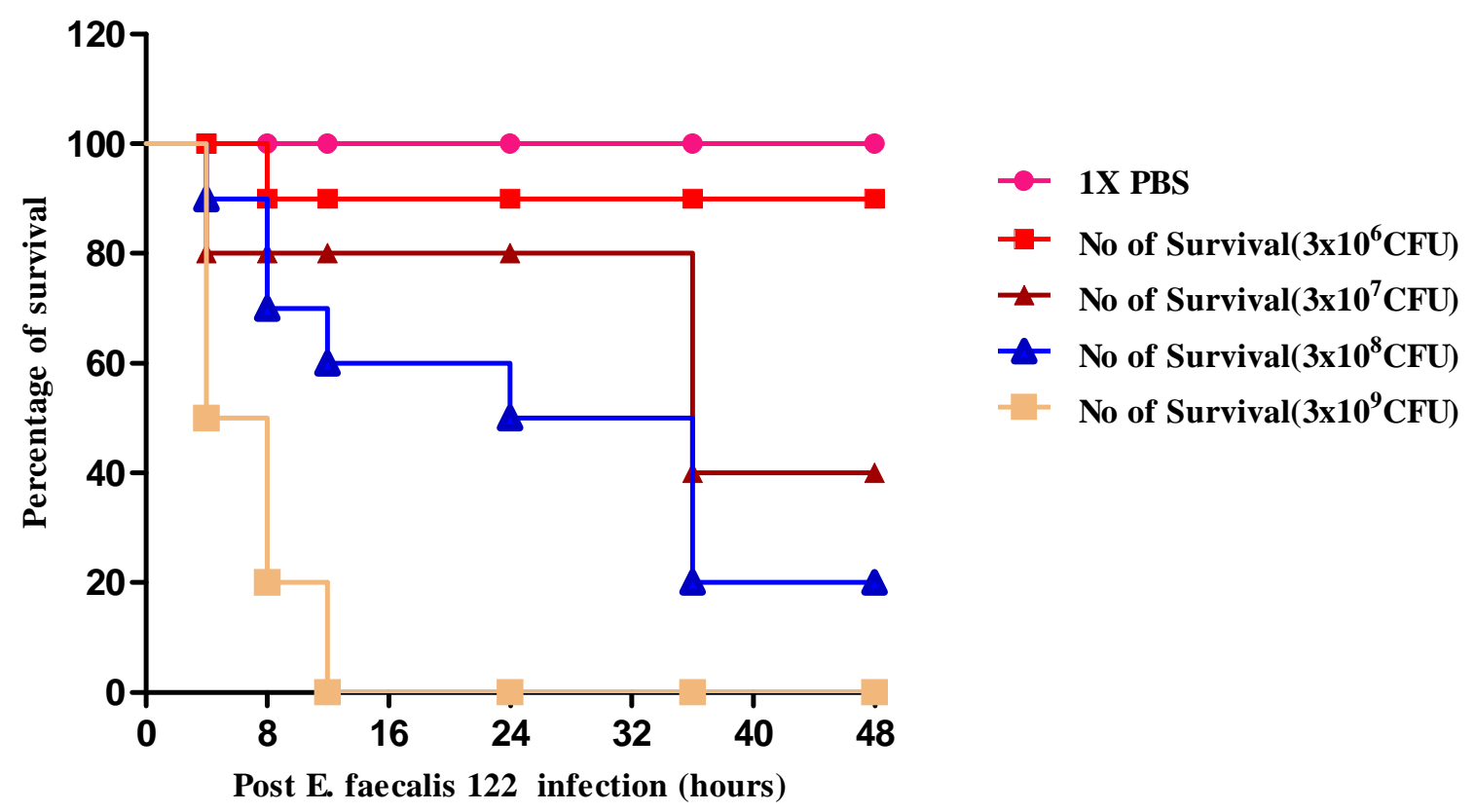

Figure 4:a.Determination of the Minimal Lethal Dose (MLD) of VREF122 in Diabetic mice $3 \times 10^{6}(\mathrm{~A}) 3 \times 10^{7}(\mathrm{~B}) 3 \times 10^{8}(\mathrm{C}) 3 \times 10^{9}(\mathrm{D}), 1 \times$ PBS Control CFU/ml represents percentage of the survival rates up to 48 hours after administration.

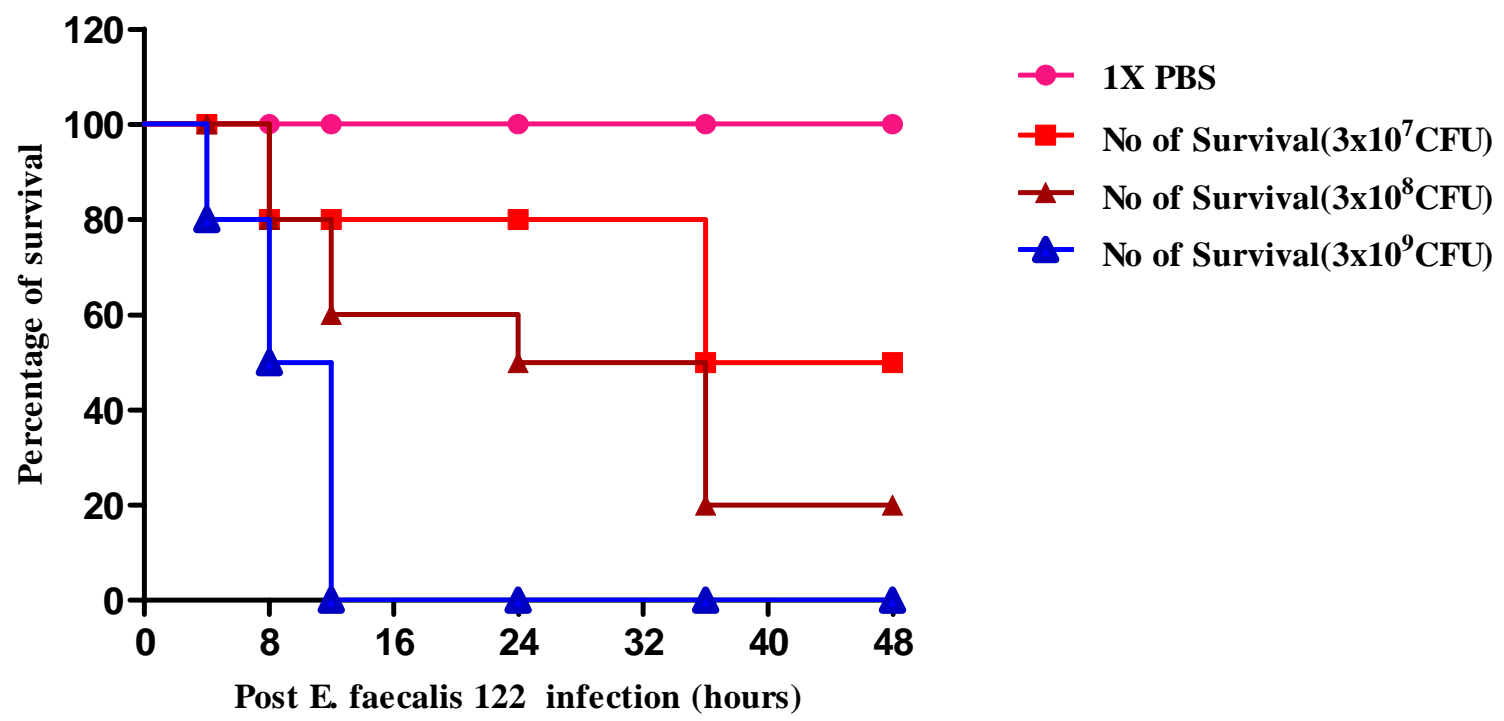

Figure.4:b.Determination of the Minimal Lethal Dose (MLD) of VREF122 in Non- diabetic Mice 1X PBS control, (A) $3 \times 10^{7}$ (B) $3 \times 10^{8}\left(C_{)} 3 \times 10^{9}\right.$ (D) $\mathrm{CFU} / \mathrm{ml}$ represents percentage of the survival rates up to 48 hours after administration. 


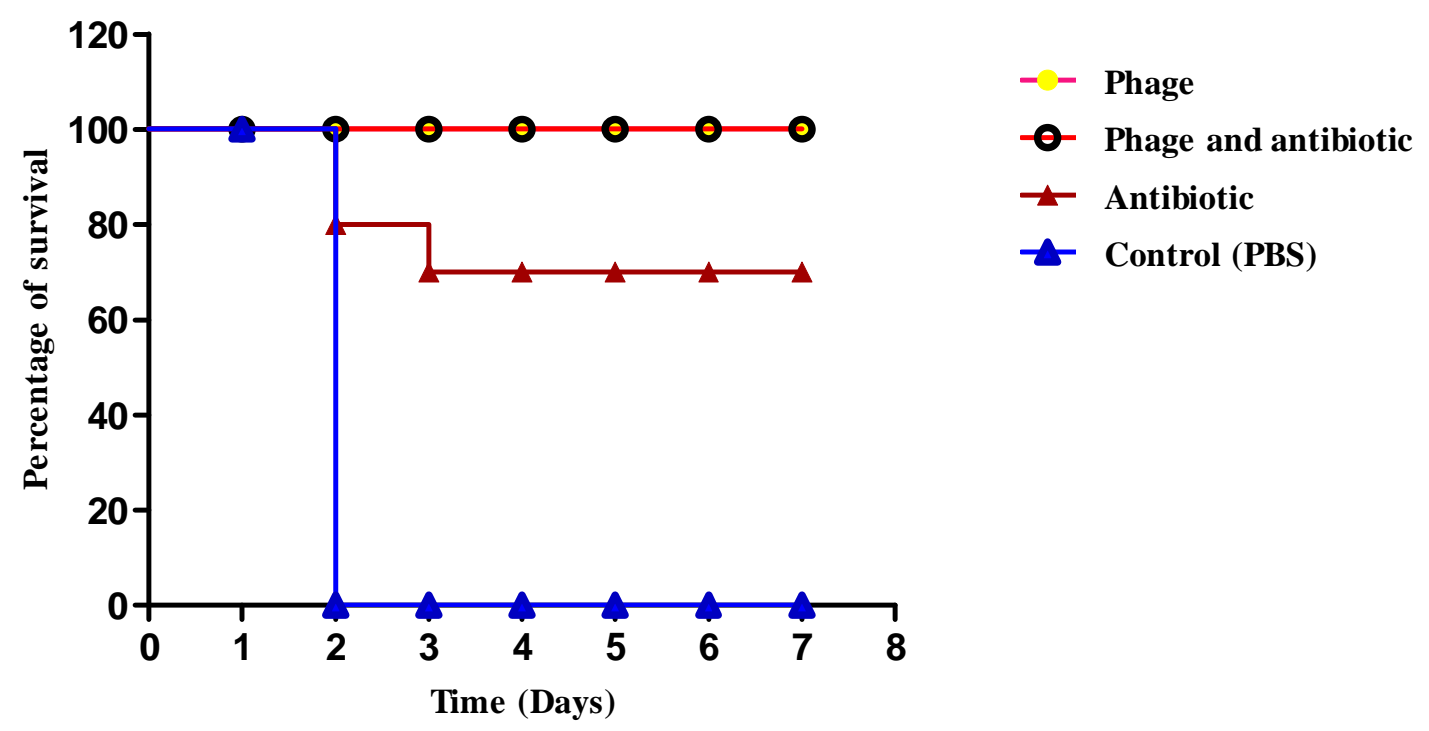

Figure.5.aDetermination of the protection of VREF122 in Diabetic mice control PBS (A) $3 \times 10^{10}$ single dose of phage (B)single dose of vancomycin antibiotic (C) $3 \times 10^{10}$ phage and single dose of antibiotic represents percentage of the survival rates up to 7 days after administration.

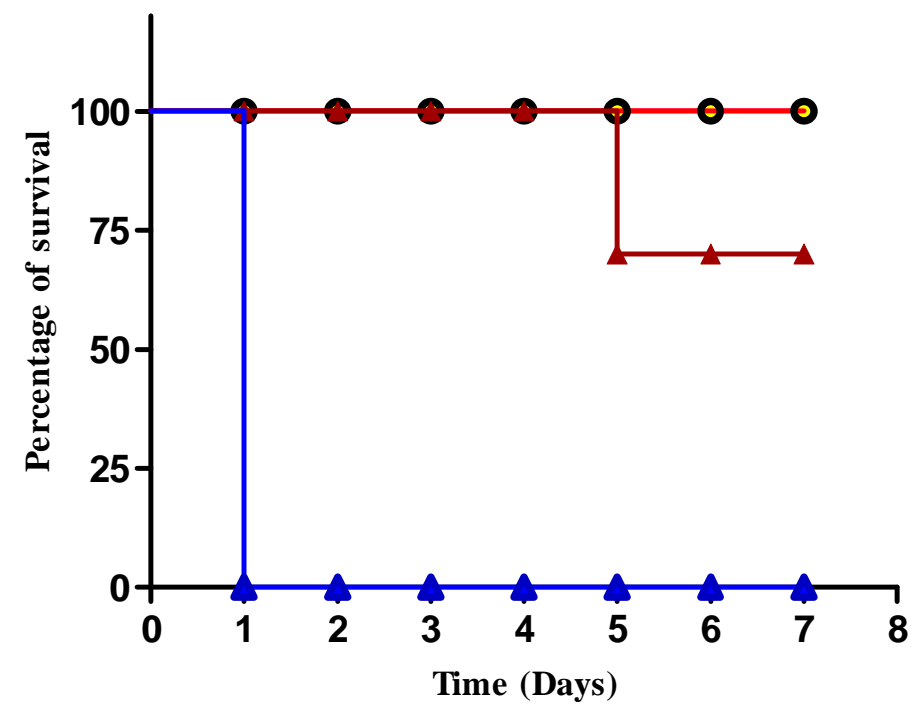

- Phage

- Phage and antibiotic

$\rightarrow$ Antibiotic

- Control (PBS)

Figure.5.bDetermination of the protection of VREF122 in Non-Diabetic mice control PBS (A) $3 \times 10^{10}$ single dose of phage (B) single dose of vancomycin antibiotic (C) $3 \mathrm{x}$ $10^{10}$ phage and single dose of antibiotic represents percentage of the survival rates up to 7 days after administration. 